\title{
Prevalence of viral hepatitis (B and C) serological markers in healthy working population
}

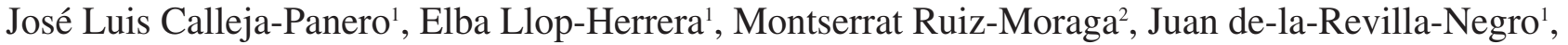 \\ Eva Calvo-Bonacho², Fernando Pons-Renedo ${ }^{1}$, José Luis Martínez-Porras ${ }^{1}$, Dolores Vallejo-Gutiérrez², \\ Carmen Arregui ${ }^{2}$ and Luis Abreu-García ${ }^{1}$
}

${ }^{1}$ Gastroenterology and Hepatology Division. Hospital Universitario Puerta de Hierro Majadahonda. Madrid, Spain. IIbermutuamur. Spain

\begin{abstract}
Introduction and objectives: prevalence of viral hepatitis $(B$ and $\mathrm{C}$ ) changes geographically. Our aim was to determinate the prevalence of hepatitis $B(\mathrm{HBV})$ and hepatitis $C$ virus (HCV) serological markers in healthy working population and to describe the epidemiological characteristics associated to its presence.

Methods: blood samples and epidemiological data of 5,017 healthy workers from Murcia and Madrid were recorded prospectively.

Results: a total of 5,017 healthy volunteers participated. Mean age $39 \pm 11$ years, men predominance (73\%). Prevalence of serological markers of $\mathrm{HCV}$ and $\mathrm{HBV}$ was $0.6 \%$ and $0.7 \%$. Age of patients with $\mathrm{HCV}$ antibody was significantly higher $(43 \pm 9$ years vs. $39 \pm 11$ years; $p=0.03$ ). We observed significant differences in liver test values (alanine aminotransferase [ALT] $64 \pm 56 \mathrm{IU} / \mathrm{L}$ vs. $28 \pm 20 \mathrm{IU} / \mathrm{L} ; p<0.001$; aspartate aminotransferase [AST] (51 $\pm 45 \mathrm{IU} / \mathrm{L}$ vs. $23 \pm 12 \mathrm{IU} / \mathrm{L} ; p<0.001)$ and in gamma-glutamyltransferase (GGT) value $(104 \pm 122 \mathrm{IU} / \mathrm{L}$ vs. $37 \pm 46 \mathrm{IU} / \mathrm{L}$; $p<0.001$. The presence of $\mathrm{HCV}$ antibody was related significantly to previous transfusion ( $13 \%$ vs. $5 \% ; p=0.03$ ), tattoos (29\% vs. $13 \% ; p<0.01)$, intravenous drug addiction (13\% vs. $0.2 \%$; $p<0.001$ ) and coexistence with people with positive HCV antibody (16\% vs. $4 \% ; p<0.001$ ). In HBV no differences in basal characteristics were observed with exception in AST values $(29 \pm 15 \mathrm{IU} / \mathrm{L}$ vs. $23 \pm 12 \mathrm{IU} / \mathrm{L} ; p<0.01)$. Hepatitis B surface antigen (HBsAg) was related significantly to previous transfusion (15\% vs. $5 \%$; $p<0.01$ ), tattoos (26\% vs. $14 \% ; p=0.04$ ) and coexistence with people with positive HBsAg (17\% vs. $4 \% ; p<0.001$ ).

Conclusions: Prevalence of serological markers in healthy working population is low. Risk factors for infection were previous transfusion and tattoos. Intravenous drug addiction was only a risk factor in $\mathrm{HCV}$.
\end{abstract}

Key words: Prevalence. Hepatitis. Viral hepatitis B. Viral hepatitis C.

Received: 03-04-2012

Accepted: 11-03-2013

Correspondence: José Luis Calleja Panero. Gastroenterology and Hepatology Division, Hospital Universitario Puerta de Hierro Majadahonda. C/ Joaquín Rodrigo, 2. 28013 Majadahonda. Madrid, Spain

e-mail: joseluis.calleja@uam.es
Calleja-Panero JL, Llop-Herrera E, Ruiz-Moraga M, de-la-Revilla-Negro J, Calvo-Bonacho E, Pons-Renedo F, Martínez-Porras JL, Vallejo-Gutiérrez D, Arregui C, Abreu-García L. Prevalence of viral hepatitis ( $B$ and $C$ ) serological markers in healthy working population. Rev Esp Enferm Dig 2013;105:249-254.

\section{INTRODUCTION}

Infections caused by viral hepatitis $\mathrm{C}(\mathrm{HCV})$ and viral hepatitis B (HBV) are one of the major causes of liver disease in the world (1) and, despite progress in the measures for its prevention and treatment, theses are still a world health and a socio-economic problem.

The World Health Organization (WHO) estimates that around 170 million of the global population is a HCV victim $(3 \%)(2,3)$ and up to 3 million people are infected de novo each year. HCV causes chronic infection in up to $70 \%$ of the infected individuals. HCV is one of the major causes of fibrosis, cirrhosis and hepatocellular carcinoma, determining an increase of the mortality among these patients $(2,4-7)$. The prevalence of infection by HCV in the European countries ranges from 0.1 to $5 \%$ (2-9). This prevalence rises significantly when patients belonging to risk groups (intravenous drug users, prison inmates) are analysed; thus the figures are between $15-90 \%$ (10). However, prevalence studies done so far are unrepresentative of the general population, because a big part is done in blood donors or pregnant women, which might underestimate the real prevalence given that individuals with risk factors are excluded. According to OMS data from two studies of global HVC prevalence of 1997 and $1999(8,11)$, HCV prevalence in Spain would be of $1.2 \%$, similar to the one in Eastern Europe countries, while the lowest rates would be found in the Nordic countries (around $0.1 \%)(8,11)$. In Spain, the record of de novo diagnosed patients is voluntary and there are no screening programmes in the general population, 
making it difficult to know exactly the current HCV prevalence. The latest prevalence study among the general population is from 2002. In this study, positive serology prevalence was $2.64 \%$ in patients older than 25 years. Prevalence was higher in individuals older than 50 years (12). In 2001, two more studies published a prevalence of 2.5 and 1.6 respectively $(13,14)$. More recent studies, only on pregnant women, showed a lower prevalence, although it is a selected population (15-17). There are no studies that examine the effect of immigration on the prevalence of HVC infection in Spain.

In the case of HBV, the WHO estimates that at the moment more than 2 billion of the global population is infected. 350 million of these people suffer from chronic hepatitis B and are at risk for developing cirrhosis, hepatocellular carcinoma and liver failure (18). Around 500,000 people infected with chronic HBV die every year because of these complications. In the areas with high prevalence, the evidence of HBsAg goes up to $8 \%$ (19) and in the areas with low prevalence the evidence of HBsAg is $<2 \%$ (18). Europe is located in an area with low prevalence, though it rises from north to south, so that Spain has a theoretical prevalence closer to $2 \%$. There are studies from the $90 \mathrm{~s}$ in Spain that place HBsAg prevalence between $1.2 \%$ and $1.7 \%(20,21)$. However, recent studies showed a fall of this prevalence down to $0.7 \%$ (22) and there is even another study in Castilla-Leon (Spain) that localized the prevalence under $0.27 \%$ (23).

Regarding risk factors related to the evidence of serological markers, it has been demonstrated that the transmission of both virus can be intravenous, sexual and perinatal. In the case of $\mathrm{HCV}$, a previous hospital stay has been shown as a risk factor in some studies $(14,24)$. In one of the epidemiological studies on HCV chronic hepatitis done in Spain was shown that hospital admission, dental procedures and previous surgery were the most frequent risk factors (12). In a similar study it was proved that tattoos, blood transfusions, intravenous drug addiction and precedent hospital stay were variables associated regardless of the infection (13). In the case of HBV, the most frequent causes are through perinatal and sexual transmission $(25,26)$. In other studies, the intravenous transmission has been analysed too as an another important way of transmission particularly in people older than 40 years in the expense of hospital stays and surgery procedures before 1990, use of non-disposable syringes or in intravenous drug users (23). Other transmission ways like coexistence with infected people have not been demonstrated properly.

Finally, the immigration's effect on the prevalence of $\mathrm{HCV}$ is unknown. Regarding HBV, the prevalence of HBsAg in immigrants is estimated around $10 \%$ (27).

Our purpose with this study was to analyse prevalence of HCV and HBV serological markers in healthy working population and to evaluate risk factors related to its presence. Moreover, immigration's effect on this seroprevalence was also evaluated.

\section{MATERIAL AND METHODS}

Blood samples and epidemiological data of a healthy working population from Murcia and Madrid were taken at their yearly check-up offered by the company's work insurance (Ibermutuamur). The epidemiological data collection was done through a fulfilling of questionnaires. From the obtained blood samples were determined the values of aminotransferases (ALT and AST) and gamma-glutamyltransferase (GGT), and serological markers of HBV (HBV surface antigen), HCV (anti-HCV) and HCV viral load.

The protocol of the study was approved by our centre's Ethics Committee. The nature of the study was explained to all the patients and all of them signed the informed consent form in accordance with the principles of the Revised Declaration of Helsinki (Edinburgh, 2000).

\section{Statistical analysis}

This is a prevalence cross-sectional study. Data analysis was performed using the SPSS software version 15.0. Data on proportions were obtained in categorical variables and data on average (standard deviation, $[\mathrm{SD}]$ ) in quantitative variables. Categorical variables were compared with $\chi^{2}$ and continuous variables with t-Student for independent data. The multivariate analysis was done with the logistic and Poisson regression.

\section{RESULTS}

From October 2007 to February 2010, 9,857 healthy workers were invited to participate in the study; 5,017 accepted and fulfilled the questionnaire. Basal characteristics of our patient population are shown on table I. Thirty one out of 5,017 gave positive results in a serological test for viral hepatitis $\mathrm{C}$ antibodies (anti-HCV), in 26 of them $(83.9 \%)$ the viral load was positive. Thirty six out of 5,017 $(0.7 \%)$ showed the presence of viral hepatitis B surface antigen (HBsAg). In our patients population there was no evidence of both markers at the same time.

We compared the basal demographic characteristics of the workers with positive anti-HCV $(n=31)$ with the ones of the workers with negative anti-HCV $(n=4,950)$. Positive HBsAg patients $(n=36)$ were excluded from the analysis. Univariate analysis results are shown on table II. Positive anti-HCV workers main age was significantly older than negative anti-HCV workers; gender was similar in both groups. There were no differences between positive anti$\mathrm{HCV}$ workers and negative anti-HCV workers regarding their work branch or the immigrant proportion. Significant differences in the liver test and GGT values were analysed. Statistically, it was meaningful the relation between positive anti-HCV and the evidence of previous transfusion $(p=0.03)$, tattoos $(p<0.01)$, intravenous drug addiction 
Table I. Basal characteristics $(n=5,017)$

\begin{tabular}{ll}
\hline Age (years) & $39( \pm 11)$ \\
Sex (M:F) & $3,660(73 \%): 1,357(27 \%)$ \\
Work branch & \\
Agricultural & $85(1.7 \%)$ \\
Construction & $813(16.2 \%)$ \\
Industrial & $813(16.2 \%)$ \\
Services & $1,951(38.9 \%)$ \\
Unknown & $1,359(27.1 \%)$ \\
Immigrant & \\
No & $4.234(84.4 \%)$ \\
Yes & $657(13.1 \%)$ \\
Unknown & $126(2.5 \%)$ \\
Laboratory data & \\
ALT (Ul/ml) & $29( \pm 21)$ \\
AST (Ul/ml) & $23( \pm 13)$ \\
GGT (Ul/ml) & $37( \pm 47)$ \\
Transmission & \\
Transfusion & $237(4.7 \%)$ \\
Tattoo & $674(13.4 \%)$ \\
Piercing & $392(7.8 \%)$ \\
Sexual transmission & $283(5.6 \%)$ \\
Parenteral drug addiction & $13(0.3 \%)$ \\
Cohabitance with a patient & \\
diagnosed of HCV or HBV & $205(4.1 \%)$ \\
Nosocomial & $2,691(53.6 \%)$ \\
\hline
\end{tabular}

$(p<0.001)$ and coexistence with people with positive anti$\mathrm{HCV}(p<0.001)$. Logistic regression analysis showed that variables independently related to positive $\mathrm{HCV}$ antibodies were: age (odds ratio [OR], 6.8; $p=0.01$ ), AST values (OR, $1.1 ; p=0.02)$, existence of tattoos (OR, $6.8 ; p=0.02)$, previous transfusion (OR, $8.0 ; p=0.02)$ and intravenous drug addiction (OR, 114.7; $p<0.001)$. Variable of coexistence with people with positive anti-HCV could not be confirmed in the multivariate analysis; however a tendency was observed (OR, 3.9; $p=0.06)$.

Positive HBsAg workers $(n=36)$ were also compared with those with negative $\mathrm{HBsAg}(n=31)$. Univariate analysis results are shown on table III. There were no significant differences in the positive HBsAg workers mean age and gender; nor in the profession and the immigration proportion. Regarding patient's basal biochemistry, differences in ALT and GGT values were not found, but in AST values. Statistically significant was the relation shown between the existence of HBsAg and previous transfusion $(p<0.01)$, tattoos $(p=0.04)$ and the coexistence with people with positive HBsAg $(p<0.001)$. By doing the multivariate analysis of the factors related to the existence of positive HBsAg, the results of the univariate analysis were confirmed, the AST (OR, 1.1; $p=0.01)$, previous transfusion $(\mathrm{OR}, 5.2 ; p=0.003)$, tattoos $(\mathrm{OR}, 3.3 ; p=0.02)$ and coexistence with people with positive $\mathrm{HBsAg}(\mathrm{OR}, 6.9 ; p<0.001)$.

Finally, we analysed if the age of our immigrant population was lower than non-immigrant population, which would partially explained the low serological markers proportion in our immigrant group. The age of the immigrant group was in fact significantly lower than the age of the non-immigrant group (37 [SD 9] vs. 40 [SD]; $p<0.001$ ) (Fig. 1).

Table II. Positive anti-HCV vs. negative anti-HCV $(n=4,981)$

\begin{tabular}{llll}
\hline & Positive anti-HCV $(n=31)$ & Negative anti-HCV $(n=4,950)$ & $p$ \\
\hline Age (years) & $43 \pm 9$ & $39 \pm 11$ & 0.03 \\
Sex (M/F) & $81 \% / 19 \%$ & $73 \% / 27 \%$ & $p=0.3$ \\
Working branch & $0 \%$ & $2.4 \%$ & $p=0.6$ \\
$\quad$ Agriculture & $30.1 \%$ & $22.2 \%$ & \\
Construction & $26.1 \%$ & $22.1 \%$ & $p=0.1$ \\
Industrial & $43 \%$ & $53.4 \%$ & $p<0.001$ \\
Services & $3.2 \%$ & $13.4 \%$ & $p<0.001$ \\
Immigrant & & & $p<0.001$ \\
Laboratory data & $64 \pm 56$ & $28 \pm 20$ & $p=0.03$ \\
ALT (IU/ml) & $51 \pm 45$ & $23 \pm 12$ & $p<0.01$ \\
AST (IU/ml) & $104 \pm 122$ & $37 \pm 46$ & $p=0.4$ \\
GGT (IU/ml) & $13 \%$ & $5 \%$ & $p=0.9$ \\
Transmission & $29 \%$ & $13 \%$ & $p<0.001$ \\
Transfusion & $3 \%$ & $8 \%$ & $p<0.001$ \\
Tattoo & $6 \%$ & $6 \%$ & $p=0.4$ \\
Piercing & $13 \%$ & $0.2 \%$ & $4 \%$ \\
Sexual transmission & $16 \%$ & $44 \%$ & \\
Parenteral drug addiction & $56 \%$ & & \\
Cohabitance with a patient diagnosed of HCV & & \\
Nosocomial & &
\end{tabular}


Table III. Positive HBsAg vs. negative HBsAg $(n=4,986)$

\begin{tabular}{llll}
\hline & AgHBs positive $(\mathrm{n}=36)$ & AgHBs negative $(\mathrm{n}=4,950)$ & $p$ \\
\hline Age (years) & $42 \pm 10$ & $39 \pm 11$ & $p=0.07$ \\
Sex (M/F) & $83.3 \% / 16.7 \%$ & $72.8 \% 27.2 \%$ & $p=0.2$ \\
Working branch & & & $p=0.7$ \\
$\quad$ Agriculture & $0 \%$ & $2.4 \%$ & \\
Construction & $20 \%$ & $22.2 \%$ & \\
Industrial & $16.7 \%$ & $22.1 \%$ & \\
$\quad$ Services & $63.3 \%$ & $53.4 \%$ & 0.6 \\
Immigrant & $17.7 \%$ & $13.4 \%$ & $p=0.1$ \\
Laboratory data & & $28 \pm 20$ & $p<0.01$ \\
ALT (IU/ml) & $33 \pm 18$ & $23 \pm 12$ & $p=0.06$ \\
AST (IU/ml) & $29 \pm 15$ & $37 \pm 46$ & $p<0.01$ \\
GGT (IU/ml) & $41 \pm 50$ & $5 \%$ & $p=0.04$ \\
Transmission & $15 \%$ & $14 \%$ & $p=0.5$ \\
Transfusion & $26 \%$ & $8 \%$ & $p=0.9$ \\
Tattoo & $11 \%$ & $6 \%$ & $p=0.08$ \\
Piercing & $6 \%$ & $0.2 \%$ & $p<0.001$ \\
Sexual transmission & $4.1 \%$ & $56 \%$ & $p=0.3$ \\
Parenteral drug addiction & $17 \%$ & & \\
Cohabitance with a patient diagnosed of HCV & $64 \%$ & & \\
Nosocomial & & & \\
\hline
\end{tabular}

\section{DISCUSSION}

In our samples, the prevalence of HCV serology was $0.6 \%$, a significantly lower figure in comparison to previous published studies $(8-11,13-16)$. We think that this figure is more in line with the current prevalence situation and that it has been affected by a rise of mortality from $\mathrm{HCV}$ that has been increasing since the $90 \mathrm{~s}$ and by a fall of acute hepatitis proportion.

In the case of HBV, HBsAg prevalence was $0.7 \%$. This prevalence was lower than the one in the studies published in the 90s, being a little higher than the one in a study published in Castilla-León with a prevalence of $<0.27 \%$ (23). In this study, age groups of children and youth were also included, and thus the population was younger than ours. Our prevalence is similar to another study published in 2007 (22). This fall can be related to the establishment of HBV prophylaxis programmes, either primary (the introduction of the HBV vaccine into children and risk groups' immunisation programmes) or secondary (gamma globulin infusion in positive HBsAg mothers' newborns). Our results

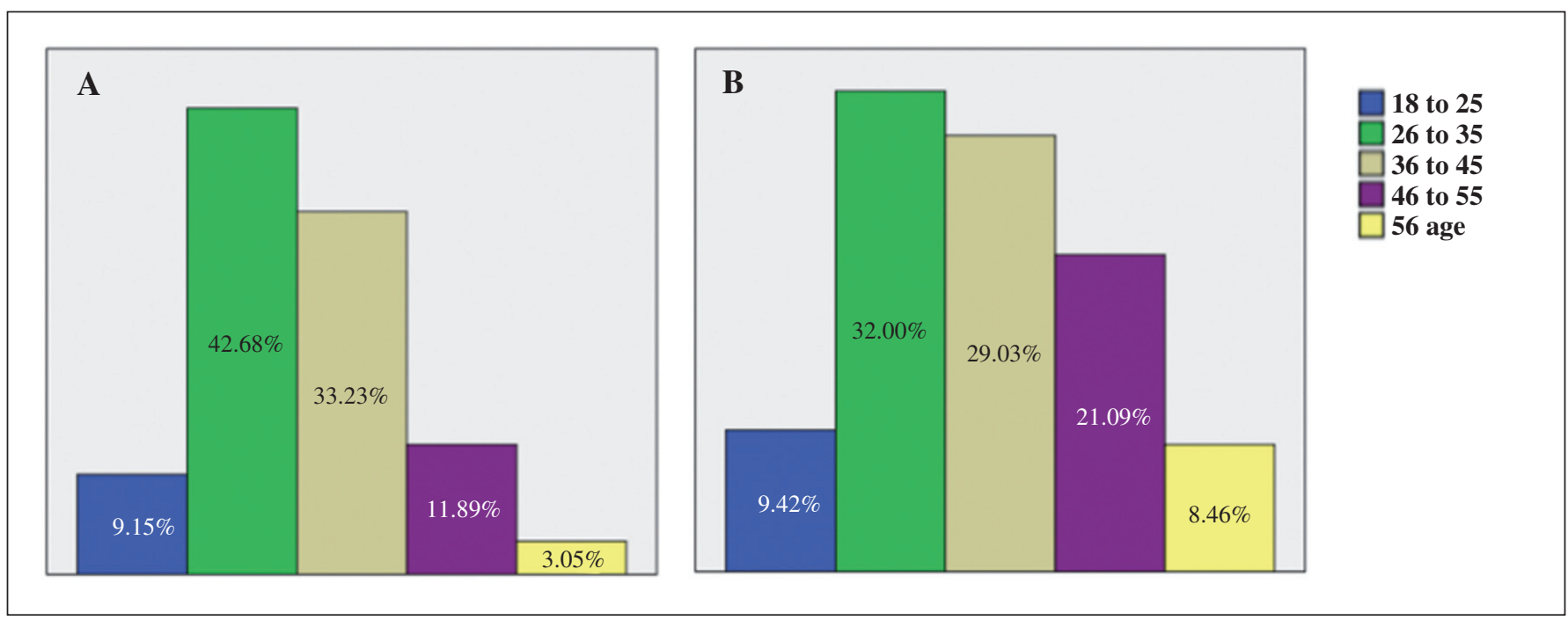

Fig. 1. Age immigrant (A) and non-immigrant (B) distribution. 
may have been also affected by a selection bias, because on one hand our study has been focused on a working population that could probably be "healthier" that a non-working population. By being a working population, people older that 65 years, in which the prevalence of viral hepatitis serological markers may probably be higher, were also excluded. Finally, some workers that did not participate could probably have said no to the study because they were aware of their seropositive condition and because of fear of work reprisals. This may get worsen in the case of immigrants.

In our study, a statistically significant relation between age and anti-HCV presence was confirmed in accordance to previous studies (12-14). Positive anti-HCV patients have also shown a liver test and GGT values significantly higher. These were not found in patients with HBsAg, being all from a similar age in comparison to the healthy group, which corroborates some previous studies published (23). This might be because in our study the participant age was more uniform by only including working population.

Is very surprising the lack of a statistically significant relation between the proportion of positive anti-HCV and HBsAg among working immigrants. In any case, the immigrant population included in this study is a selected population because they are immigrant subjects that work legally in Spain and are younger than non-immigrants.

Finally, regarding the ways of transmission of $\mathrm{HCV}$ and HBV infections, previous studies results are confirmed $(12,13,23,25,26)$. In the case of anti-HCV transfusion, tattoos and intravenous drug addiction; and in the case of HBsAg previous transfusion and tattoos are significantly related to the prevalence increase of serological markers. Hospital stay was not connected to a rise in the infection rate. In both cases, there is another potential way of transmission not confirmed in previous studies (28) and this is the coexistence with people with HCV and HBV positive serological markers. For sexual transmission, not confirmed in the case of HBsAg, it might be due to the way data have been collected in form of questionnaire that people did not answer with the truth.

In conclusion, the prevalence of HCV and HBV serological markers in our healthy working population is low. We demonstrate a significant statistically relation between the coexistence with infected people and the presence of $\mathrm{HCV}$ and HBV serological markers.

\section{REFERENCES}

1. Rehermann B, Nascimbeni M. Immunology of hepatitis B virus and hepatitis C virus infection. Nat Rev Immunol 2005;5:215-29.

2. Global surveillance and control of hepatitis C. Report of a WHO Consultation organized in collaboration with the Viral Hepatitis Prevention Board, Antwerp, Belgium. J Viral Hepat 1999;6:35-47.

3. EASL International Consensus Conference on hepatitis C. Paris, 26-27 February 1999. Consensus statement. J Hepatol 1999;31(Supl. 1):3-8.

4. Omland LH, Krarup H, Jepsen P, Georgsen J, Harritshoj LH, Riisom $\mathrm{K}$, et al. Mortality in patients with chronic and cleared hepatitis $\mathrm{C}$ viral infection: A nationwide cohort study. J Hepatol 2010;53:36-42.

5. Omland LH, Jepsen P, Krarup H, Schonning K, Lind B, KromannAndersen $\mathrm{H}$, et al. Increased mortality among persons infected with hepatitis C virus. Clin Gastroenterol Hepatol 2011;9:71-8.
6. Lauer GM, Walker BD. Hepatitis C virus infection. N Engl J Med 2001;345:41-52.

7. Omland LH, Farkas DK, Jepsen P, Obel N, Pedersen L. Hepatitis C virus infection and risk of cancer: A population-based cohort study. Clin Epidemiol 2010;2:179-86.

8. Hepatitis C: global prevalence (update). Wkly Epidemiol Rec 1999; 74:425-7.

9. Sacristán B, Gastañares MI, Elena A, Sacristán M, Barcenilla J, García $\mathrm{JC}$, et al. Seroepidemiologic study of hepatitis $\mathrm{C}$ virus infection in a general population from the region of La Rioja, Spain. Med Clin (Barc) 1996;107:331-5.

10. Esteban JI, Sauleda S, Quer J. The changing epidemiology of hepatitis C virus infection in Europe. J Hepatol 2008;48:148-62.

11. Hepatitis C: global prevalence. Wkly Epidemiol Rec 1997;72:341-4.

12. Sola R, Cruz de Castro E, Hombrados, Planas R, Coll S, Jardí R, et al Prevalence of hepatitis B and hepatitis $C$ viruses in different counties of Catalonia, Spain: Cross-sectional study. Med Clin (Barc) 2002; 119:90-5.

13. Domínguez A, Bruguera M, Vidal J, Plans P, Salleras L. Communitybased seroepidemiological survey of HCV infection in Catalonia, Spain. J Med Virol 2001;65:688-93.

14. Forns X, Martínez-Bauer E, Feliú A, García-Retortillo M, Martín M, Gay E, et al. Nosocomial transmission of HCV in the liver unit of a tertiary care center. Hepatology 2005;41:115-22.

15. Gutiérrez-Zufiaurre N, Sánchez-Hernández J, Muñoz S, Marín R, Delgado N, Saenz MC, et al. Seroprevalence of antibodies against Treponema pallidum, Toxoplasma gondii, rubella virus, hepatitis B and C virus, and HIV in pregnant women. Enferm Infecc Microbiol Clin 2004;22:512-6

16. Suárez González A, Solís Sánchez G, Otero Guerra L, Viejo De La Guerra G, Álvarez Navascués C, García López R. Prevalence of immunity to hepatitis viruses in pregnant women from the health area of Gijón (Spain). Gastroenterol Hepatol 2004;27:347-52.

17. Muñoz-Almagro C, Juncosa T, Fortuny C, Guillen JJ, González-Cuevas A, Latorre C. Prevalence of hepatitis C virus in pregnant women and vertical transmission. Med Clin (Barc) 2002;118:452-4

18. Goldstein ST, Zhou F, Hadler SC, Bell BP, Mast EE, Margolis HS. A mathematical model to estimate global hepatitis B disease burden and vaccination impact. Int J Epidemiol 2005;34:1329-39.

19. Alter MJ. Epidemiology of hepatitis B in Europe and worldwide. J Hepatol 2003;39(Supl. 1):S64-9.

20. Domínguez A, Bruguera M, Vidal J, Plans P, Salleras L. Changes in the seroepidemiology of hepatitis B infection in Catalonia 1989-1996. Vaccine 2000;18:2345-50.

21. Salleras L, Bruguera M, Vidal J, Taberner JL, Plans P, Bayas JM, et al. Prevalence of hepatitis B markers in the population of Catalonia (Spain). Rationale for universal vaccination of adolescents. Eur J Epidemiol 1992;8:640-4.

22. Salleras L, Domínguez A, Bruguera M, Plans P, Costa J, Cardenosa $\mathrm{N}$, et al. Declining prevalence of hepatitis B virus infection in Catalonia (Spain) 12 years after the introduction of universal vaccination. Vaccine 2007;25:8726-31.

23. López-Izquierdo R, Udaondo MA, Zarzosa P, García-Ramón E, Garcinuno $S$, Bratos MA, et al. Seroprevalence of viral hepatitis in a representative general population of an urban public health area in Castilla y Leon (Spain). Enferm Infecc Microbiol Clin 2007;25:317-23.

24. Bruguera M, Forns X. Hepatitis C in Spain. Med Clin (Barc) 2006; 127:113-7.

25. Larranaga JR, Ardiz T, Del Blanco D, Vázquez Gallardo R. Incidence of B virus in the prostitute population of Vigo. Rev Clin Esp 1989; 185:44.

26. Requena Caballero L, Requena Caballero C, Requena Caballero I, Sánchez López M, Vázquez López F, Romero Guerrero J, et al. Prevalence and risk factors of hepatitis B in Spanish prostitutes. Epidemiol Infect 1987;99:767-74.

27. Pérez-Molina JA, Herrero-Martínez JM, Norman F, Pérez-Ayala A, Monge-Mahillo B, Navarro-Beltra M, et al. Clinical, epidemiological characteristics and indications for liver biopsy and treatment in immigrants with chronic hepatitis B at a referral hospital in Madrid. J Viral Hepat 2011;18:294-9.

28. Diago M, Zapater R, Tuset C, Carbonell P, González C, Cors R, et al. Intrafamily transmission of hepatitis $C$ virus: Sexual and non-sexual contacts. J Hepatol 1996;25:125-8. 